\title{
PERSONAJES EN TRASIEGO: JUEGOS CERVANTINOS DE G. TORRENTE BALLESTER
}

\author{
«Sólo por la literatura se justifican los \\ hechos literarios». \\ TORRENTE BALLESTER, \\ Fragmentos de Apocalipsis, 311
}

Desde que oí el término, 'trasiego', su densa eufonía me llevó a imaginar un rumor de viento, de pasos, los pasos de las eses que, transformadas en seres caminaban de un lugar a otro en misiones propias o ajenas. Por ello, al tener que formular el título de este trabajo, en el que intentaré examinar la estrategia narrativa del «robo de personajes», se me impuso, fulgurante, como el más adecuado.

Alguien podría objetarme que el verbo 'trasegar' se utiliza para indicar el travase de líquidos de una vasija a otra. De manos a boca se me ocurre que, dada la dificultad para determinar la materia que conforma a los entes de ficción, puedo atreverme, con fantasía hermenéutica, a darles cuerpo de arena, agua de piedra. Pienso que la metáfora puede funcionar, justificando el uso de la mencionada voz.

Estos personajes, codificados en un juego combinatorio, se van a ver desplazados (siguiendo las estrategias de otro jugador) a una nueva partida. Ésta va a ser jugada en doble tablero: el de procedencia y el de llegada. Creo necesario añadir que, en algunas ocasiones, al expediente literario del hurto va a correr paralelo (en mayor o menor medida) el de la manipulación (y tal vez, malogro) de los personajes. En nuestro caso, ambos elementos encuentran su derecho de comparación al articularse como los medios a través de los cuales se desarrolla el tema de la invalidación de un apócrifo. Las obras y los personajes que van a cruzarse son: la Segunda Parte del Quijote 1 y el Quijote ${ }^{2}$ de Avellaneda con Alvaro Tarfe; "Un

\footnotetext{
1 M. DE CERvantes, Don Quijote de la Mancha, II, ed. introd. y notas de M. DE RIQUER. Barcelona, Planeta, 1992.

2 A. FERnÁNDEZ De Avellaneda, El ingenioso hidalgo Don Quijote de la Mancha, ed. de F. García SALINERo. Madrid, Castalia, 1987.
} 
problema final» y El valle del miedo ${ }^{3}$ de Conan Doyle y Fragmentos de Apocalipsis ${ }^{4}$ de Torrente Ballester con el profesor Moriarty. Dicha estrategia va a tener ulteriores ecos dentro de esta novela, respondiendo a la estructura de la mise en abyme. Paradigma estructural de la novela, es pertinente señalar aquí su utilización al elaborar la Narración apócrifa del Supremo y las «Secuencias proféticas» atribuidas a don Justo Samaniego (ambas en relación al «Diario» y a las «Narraciones» del autor). Moriarty es la señal declarada de la operación que va a multiplicarse dentro de la escritura de Fragmentos, constituyendo un aspecto de la construcción laberíntica de las voces autoriales y el vórtice de un concéntrico juego de refracciones que procede a través de reflejos y desdoblamientos.

1. En su creativo ensayo El Quijote como juego ${ }^{5}$, G. Torrente Ballester denomina «segundo collage» al episodio donde hace su aparición don Alvaro Tarfe dentro del Quijote de 1615. Este procedimiento narrativo funciona en el tema del 'reconocimiento' y marca su conclusión. Don Quijote, alcanzada su aspiración de verse convertido en personaje literario como los héroes de sus lecturas, no sólo quiere ser reconocido como quien es sino también como quien no es. En esta óptica, el personaje del apócrifo es convocado por Cervantes para ratificar la identidad de su(s) personaje(s) y de su obra $^{6}$. Don Quijote, hombre de papel y de palabras es afirmado por quien también procede de un universo literario y el pacto se ratifica, precisamente, mediante un papel y unas palabras ${ }^{7}$. En Fragmentos, metanovela por excelencia, Torrente Ballester también evoca y hace comparecer a un personaje libresco, el prof. Moriarty antagonista de Sherlock Holmes.

Creo que, llegados a este punto, conviene dar unas indicaciones sobre algunos aspectos de la estructura de Fragmentos. A grandes

3 El primero es un relato que se encuentra dentro de Las memorias de Sherlock Holmes (1897); el segundo es una novela que CONAN DOYLE publicó en 1915. Ninguna de las dos obras va a ser citada en el texto de TORRENTE.

4 Barcelona, Destino, 1997. De ahora en adelante el texto se citará como Fragmentos.

5 Madrid, ed. Guadarrama, 1975, pp. 169-212 [208-209]. TORRENTE BALlESTER, autor de reconocida tradición anglocervantina, durante la composición de Fragmentos trabaja asimismo en la elaboración del ensayo sobre el Quijote. Cfr. I. CASTELls, «La novela como juego: Cervantes y Torrente Ballester», en Actas del tercer Congreso Internacional de la Asociación de Cervantistas. Palma, UIB, 1998, pp. 643-653.

6 Para profundizar la paradójica dicotomía entre el papel que en este juego representan don Quijote y CERVANTES, cfr. el clásico estudio de M. FouCAULT, Les mots et les choses. Paris 1966, trad. it. Milano, Rizzoli, 1967, pp. 61-65.

7 A este propósito cfr., el excelente artículo de G. CALABRó, "Le occasioni di un apócrifo", en Identità e metamorfosi del barocco ispanico, a cura di G. CALABRò. Napoli, Guida ed., 1987, pp. 11-42 [38]. 
rasgos, la obra se presenta como el «Diario de trabajo» de un escritor (Torrente se propone como autor-personaje que intentará explicar cómo va construyendo una novela); las secuencias que de ésta va creando, a las que da el título de "Narraciones», y otras secuencias, las denominadas «Proféticas» cuya composición delega a otro personaje-narrador. En este dédalo de voces e invenciones, la convención se complica y aparecen unas páginas cuya autoría es presentada como ignota: el autor-personaje las señala como Narración (III-apócrifa ${ }^{8}$. Así lo declara a su interlocutora cuando ésta le interroga sobre su expresión perpleja:

«¿Sucede algo?» «Sí. Que yo no soy el autor de este capítulo» ${ }^{9}$.

2. Hay por lo tanto otro creador que anda en juego. Juego peligroso porque se propone en el texto como una amenaza para con la identidad y la función del autor-protagonista, quien así expresa su desasosiego:

pero con la seguridad de que yo no lo había inventado y el temor de que él me hubiera inventado a mí, pues aquella sensación de que otro me estaba pensando permanecía ${ }^{10}$.

El autor, desde el principio del texto, nos advierte de la condición múltiple de su yo: Napoleón, los heterónimos, los desconocidos que pueblan su interior. Va a ser entre estos últimos donde se concretizará la figura del usurpador, quien más adelante se identifica con estas palabras:

Soy el mismísimo Supremo, ese que manda. El que maldices o bendices todos los días como oración de la mañana o de la noche, según te hayas beneficiado de mí o no hayas sabido aprovecharte. El Supremo, ya sabes. Casi nadie ${ }^{11}$

Torrente se divierte moviendo los hilos de sus marionetas, y se presenta como el primer autor, él mismo muñeco de palabras. En

8 En esta narración se relata la visión que el bonzo Ferreiro tiene de los universos en perenne retorno. La estrategia de que un episodio en extremo fantástico sea contado por otro narrador, puede funcionar para preservar la credibilidad del autor. Dicha estrategia recuerda la que usa CERvANTES al hacer, como es bien sabido, que sea un historiador árabe, Cide Hamete Benengeli, el encargado de recopilar las hazañas de don Quijote. Es notoria la creencia común de que los árabes podían ser, con facilidad, embusteros. De esta manera, si el relato de la historia no resulta fidedigno, el autor queda libre de responsabilidades.

9 Fragmentos, p. 228.

10 Ibid., p. 243.

11 Ibid., p. 245. 
el elaborado encuentro/contienda con su doble más potente, cuestiona la propia identidad como artífice y como personalidad. Su pugna dialéctica se propone en términos de antagonismo excluyente total. Leamos un fragmento de este diálogo:

[Supremo] «Lo que se dilucida, le respondí, es si yo le inventé a usted o usted me inventó a mí.

$[\ldots]$

[autor] Admito, como posibilidad remota, que usted me esté pensando, pero admita que al mismo tiempo yo lo estoy pensando a usted». [Supremo] " ¿Y qué se infiere?» [autor] "Que ha habido un error o, si usted prefiere, una interferencia.» [Supremo] «Me resulta difícil explicarlo, pero, si admite que lo he imaginado, la cosa queda clara. Usted es un personaje de mi novela.» [autor] «¿De la suya?» [Supremo] «Sí. De esa que lleva en la cartera y que yo le he dictado desde el principio al fin. Puedo contársela de pe a pa, si lo desea» ${ }^{12}$.

Son secuencias donde Torrente Ballester llena sus páginas de espejos, juega hasta el absurdo (pero con gran verosimilitud) el expediente del apócrifo transformándolo en total mixtificación. El círculo se tensa transformándose en elipsis, hasta rasgarse. Ya no se trata solamente de dilucidar la cualidad apócrifa de unas páginas sino de afirmar la propia autoría respecto a la totalidad del texto. Plantea el tema como un pulso de voluntades y organiza la escena de la victoria sobre la turbación que estaba por anonadarlo, a través de la tríade, tenacidad, energía y fortuna. Se hace así de nuevo con su papel de titiritero-demiurgo, aclara la proveniencia del apócrifo y aleja a su creado enemigo. Propone su derrota pero no su destrucción. En ello está Moriarty, le ha confesado el perdedor...

El Supremo [su doble] había encargado de mi persecución y muerte nada menos que al doctor Moriarty, el cerebro del crimen en todo el mundo ${ }^{13}$.

3. La aparición sucesiva de Moriarty se verá formalizada, en términos más articulados, y, en este caso, quien va a evocarlo y a hacerlo funcionar en su ficción va a ser el primer autor. Como veremos, los expedientes mediante los que el famoso inglés es introducido en el texto son disímiles a los utilizados por Cervantes, ya que presentan variantes: a) en las modalidades de su aparición; b) en la relación entre su mundo de procedencia y el del texto («Narraciones»); c) en relación con el apócrifo. No muda, aunque pre-

12 Ibid., pp. 243-244.

13 Ibid., p. 251. El mismo TORRENTE, en el "Prólogo» a la 2.a edición, señala la procedencia quijotesca del expediente que va a utilizar. Según G. GENETTE, (Palimsestes. Paris, ed. du Seuil, 1982, p. 8), nos encontramos pues ante un plagio declarado. 
senta una articulación compleja hasta el paroxismo, el papel para el que ha sido transferido. El autor le convocará con urgencia para salvar y reorganizar su propia novela, constituyéndolo en protagonista de uno de los juegos de disgregación y apropiación que recorren el texto. Moriarty, también él hombre de palabras, viajará dentro de las de otro apócrifo para intentar cancelar el peligro de interferencias destructivas en la obra.

Las razones y modalidades a través de las cuales Cervantes hace comparecer y funcionar, en su novela, al caballero granadino de Avellaneda quedaron precedentemente apuntadas y, el haber sido éstas objeto de múltiples y excelentes estudios ${ }^{14}$, me permite remitirme a ellos y proceder directamente en el análisis del expediente literario usado por Torrente en Fragmentos.

En el prólogo a su segunda edición (1977) el autor gallego explica al lector ante qué tipo de obra se encuentra. Su clave de lectura sería la transparencia y su riesgo o finalidad implícita, la descodificación del género novelesco. Aquí Torrente remite al significado etimológico del término 'apocalipsis', que en griego significa descubrir y poner de manifiesto lo que está escondido. Será por ello por lo que, al levantar el velo que oculta la verdad de la existencia y, en este caso el engranaje de la escritura, se muestre inevitablemente el horror, la desvastación o el juego. Entre los artificios señalados Torrente indica, socarronamente, el del robo de los personajes. Leamos sus palabras:

\begin{abstract}
Cervantes inauguró (que yo sepa) un truco o audacia, o delito, cometido por otros muchos después: a veces lealmente, con nombre y apellidos; a veces, cambiando la apariencia, a ver si cuela: me refiero al robo de un personaje ajeno y su introducción en la propia ficción. Cervantes lo hizo con don Álvaro Tarfe; otros se aprovecharon del mismo modo de las creaciones de Cervantes, y yo, en estos Fragmentos... echo mano del doctor Moriarty, el enemigo de Sherlock Holmes: lo hice porque me divertía, porque se me ocurrió, y porque Moriarty, lo mismo que Sherlock Holmes, son ya bienes mostrencos, y a nadie le parece mal su explotación [...] lo puse también en práctica, como recurso cómico, en el interior mismo de Fragmentos... y con sus propios materiales ${ }^{15}$.
\end{abstract}

Algo más adelante (siempre en el prólogo) el autor retomará el discurso para indicar las ramificaciones del expediente, dejando en

\footnotetext{
14 Además del citado ensayo de G. Calabrò, quiero recordar los trabajos de: S. Gilman, Cervantes y Avellaneda. México, Colegio de México, 1951; E. C. Riley, Teoría de la novela en Cervantes. Madrid, Taurus, 1971; L. SPITZER, "Perspectivismo lingüístico en el Quijote», en Lingüística y historia literaria. Madrid, Gredos, 1982, pp. 57-106; M. Moner, Cervantès conteur. Madrid, Casa de Velázquez, 1989; J. M. MARTín MORÁN, El Quijote en ciernes. Alessandria, Ed. dell'Orso, 1990.

15 Fragmentos, pp. 20-21.
} 
punta de alfiler el origen de un hilo a seguir, hilo y laberinto que van a identificarse en lo que podría llamarse el segundo juego de las autorías.

4. Creo que es hora de que nos acerquemos a lo que podemos llamar «razones y sinrazones de un apócrifo».

¿Cuáles son los motivos por los que el poderoso Supremo se ha infiltrado en la novela del autor, causándole una crisis existencial y creativa? Torrente pone aquí en discusión paródica los temas del escritor esquizofrénico y de la autonomía de los personajes. El esquema de la acción está expuesto como una red cuyo cabo, al ser tirado, da como resultado: el potente por antonomasia es perseguido; siendo también él un escritor ${ }^{16}$ escribe una novela y se refugia en ella. Al relatar sus peripecias de fuga con su joven amante Lenn, el Supremo cuenta:

[refiriéndose a las palabras de Lenn y luego las propias] Concluyó resignadamente que, toda vez que ella no se atrevía a matarme, que podía matarla yo a ella y suicidarme después. Llegué a creer que no había otro recurso, hasta que me acordé de las novelas. Yo las había escrito, podía inventar otra nueva en que cupiéramos los dos. [...] Por eso estamos en la novela, Lenn y yo ${ }^{17}$.

La obra literaria como refugio de un creador ya había sido propuesta precedentemente en las dos autobiografías de otras personalidades del autor: la del agente secreto que, en explícito homenaje a Borges lleva por nombre el Maestro de las pistas que se bifurcan y la del autor-escritor en su pacto con Lenutchtka. El primer caso es también una estrategia para escapar a una persecución:

[...] por eso me he refugiado en el interior de esta novela, mero conjunto de palabras, como el gusano se esconde en el ovillo que él mismo se fabrica $^{18}$.

En el segundo, el expediente funciona como refugio que permite la historia de amor entre un maduro autor gallego y una joven estudiosa de Leningrado, quien en la ficción propone que

[...] la metiera también en la novela; es decir, la redujese a mi misma condición de sistema verbal para que así los dos, en el relato, pudiésemos amarnos ${ }^{19}$.

\footnotetext{
16 «No por ganar dinero, que me sobraba, sino para disimular mejor, me hice escritor", Fragmentos, p. 250.

17 Ibid., p. 251. La cursiva es mía.

18 Ibid., p. 64

19 Ibid., p. 161.
} 
Cobijo de peligro, regazo de amor. Acciones, estructuras y tipologías se articulan complementándose y se proponen como núcleos de la construcción en abyme de la que la secuencia del Supremo será reflejo y espejo.

El complejo diseño de la figura del Supremo ( el sosia inicial, polo de negativos y la multiplicación de copias posteriores) y su papel dentro del texto, puede responder a la decisión autorial de presentar a su doble más ignominioso, el del hombre de poder (ese Poder que Torrente combate en todas sus obras), su enfrentamiento y su derrota. Este doble simbólico volverá a salir en la obra pero su propuesta será menos angustiosa y trágica, mera parodia del dictador latinoamericano ${ }^{20}$.

Y si el Supremo es, como creemos, un doble del autor, el apócrifo no es más que su empleo como tópico literario. Es un apócrifo de juego. Es un apócrifo que no lo es tanto. Un peligro creado desde dentro y allí mismo anulado. Más adelante veremos cómo.

5. En el Quijote el peligro llega de fuera, del mundo real y Cervantes hace que sea su héroe el que se encargue de consolidarse como quien desea ser. Por lo que concierne al proyecto de la obra cervantina, el ataque de Avellaneda es desvastador, y, de reflejo, Cervantes así lo propone en don Quijote. Literatura contra literatura: una sola obra, un solo autor, un solo héroe deben subsistir. Cervantes construye la destrucción del apócrifo negando su credibilidad por medio de uno de los coprotagonistas más relevantes del falso Quijote: Álvaro Tarfe. Éste, con su tipología íntegra, es elegido para desmentirlo a través de su actuación al mismo tiempo que, con su inclusión en el mundo cervantino, señala la anulación del mundo de partida. Don Álvaro ha sufrido un encantamiento y lo que ha visto y vivido precedentemente es sólo fruto de una magia falaz. El recurso a los encantadores, que constituye uno de los resortes explicativos y afirmativos de las extravagancias a las que don Quijote debe de hacer frente, funciona ahora para desechar, cancelar el universo de procedencia y la misma sombra de Tarfe en él, insertándolo en el universo de llegada como el propio, el único, el «real».

Si el apócrifo torrentino es un juego literario, a mayor razón se presenta como pertinente la implicación de Moriarty en la pesquisa que, sobre el sobreviviente falsario, va a encomendarle el autorpersonaje. Puro ente literario se revela más que idóneo para moverse dentro de los universos de ficción. Sus capacidades resultan

20 Es el texto perteneciente a las entradas del diario del 4 y 5 de noviembre donde el autor-personaje se desplaza a la novela del Supremo y se cuentan sus experiencias en la isla Margarita. Ibid., pp. 321-334. 
verosímiles y eficaces en cuanto al trato y al paso a través de los materiales construidos por la escritura. Ya no se trata ahora de destruir un peligro respecto a la autenticidad de la autoría sino, como se ha indicado, de neutralizar posibles interferencias nefastas sobre los personajes de las «Narraciones» - el robo y el malogro de Pablo Bernárdez-, y del mismo «Diario» -el intento de aniquilación de Lenutchka-, maniobras menos directas que la anterior pero símilmente perturbadoras. Su viaje va a ser ahora del universo implícito de Conan Doyle ${ }^{21}$ al texto de Torrente donde se está contando la elaboración de una novela, para pasar ulteriormente a la novela paralela que se supone que está escribiendo el Supremo y en la que éste habita. Moriarty entra en la ficción, como se vio anteriormente, en la escena donde Lenutchka, después de haber sido víctima de la voluntad destructiva de otro creador, expresa su miedo identificándole con el inglés. Su nombre hará surgir, de nuevo, la estrategia del robo implícito pues el primer autor indica que el problema puede solucionarse 22

«Metiendo a Moriarty en la novela. Sin más preámbulos, inmediatamente». Y en aquel mismo momento llamaron a la puerta, fui a abrir, y el profesor Moriarty esperaba, con el sombrero en la mano y una sonrisa horripilante debajo del bigote ${ }^{23}$.

Torrente construye la escena de las presentaciones y la exposición del problema sobre formalidades de guiño irónico. Moriarty, diabolus ex machina, va a desplegar su función. Debe encontrar al Supremo y para ello ha de desplazarse de un sistema escritural a otro. El paso se organiza remitiendo al expediente de la fórmula mágica que le permite forjar un pasaje entre ellos y facilitar un especial descenso ad inferos. Ante las páginas de la Narración apócrifa recitará la fórmula que destruirá parte del texto, proporcionándole la vía de enlace. Ésta es la hilarante y «eficaz» retahíla:

21 Como ya se apuntó, las novelas, que consituyen el mundo de procedencia, no se mencionan. Se dan por supuestamente conocidas, vista la fama de su autor.

22 Su introducción en el texto recuerda las modalidades con las que CONAN DOYLE le hace comparecer en la escena de "Un problema final»: [Holmes] «Estaba sentado en el salón reflexionando sobre la situación cuando se abrió la puerta y me encontré delante al profesor Moriarty», en Las memorias de Sherlock Holmes. Madrid, Anaya, 1988, p. 306.

23 Fragmentos, p. 303. La simpatía de TORRENTE BALlESTER por los personajes de ConAN Doyle hace que en 1979, en su cuento "Mi reino por un caballo» (recogido ahora en Historias de amor para eruditos. Barcelona, Planeta, 1995, pp. 7120 [38-39] vuelva a jugar con la clásica pareja Sherlock Holmes-doctor Watson, con la tipología completamente invertida: aquí Watson es quien deduce y Holmes quien intuye acientíficamente. 
«Quien sea yo por delante, el que viene diciendo yo por detrás, desde que empezaron estas páginas por delante, ¿qué importa a nadie por detrás? Sin embargo, por delante, ahora me dieron ganas de declararlo por detrás...»[...] Y así continuó, impertérrito, hasta que destruyó el parlamento completo por el que el Supremo nos había comunicado quién era ${ }^{24}$.

Torrente, como Cervantes, respeta asimismo la tipología del personaje robado, potenciando en este caso su astucia e inteligencia pero no su crueldad. Prosiguiendo la lectura sabremos que, ganada la confianza del Supremo, se convertirá en el máximo exponente de control de su mundo. Un mundo que va apartándose definitivamente del de las «Narraciones», finalidad para la que Moriarty había sido reclamado. El primer autor va a recuperar la autonomía sobre el texto ya que Moriarty va a lograr, con su juego de dispersiones, neutralizar al Supremo. Para la credibilidad de la situación, Torrente lo presenta escondiendo su identidad y creando a su vez un propio y fantasmagórico doble hacia el que dirigir la obsesión persecutoria del dictador antillano. Todo se invierte: éste parece ser también uno de los postulados de Fragmentos.

6. Dos son las señales implícitas con las que Torrente indica el nuevo dominio del autor respecto a las «Narraciones»: 1) Pablo Bernárdez, que parecía malogrado por el Supremo, vuelve a funcionar según las propias coordenadas establecidas; 2) la Narración apócrifa se convierte en el motor de una parte de las "Narraciones» (hace posible el viaje de Pablo y Juanucha hacia el pasado) y, en una consecuente y verosímil manipulación del autor, éste atribuye al bonzo Ferreiro ( protagonista del apócrifo) la frase que explicita la visión de la futura destrucción de Villasanta. El final apocalíptico debería estar anunciado en las «Secuencias Proféticas ${ }^{25}$ ». En cambio, el primer narrador la hace derivar de la Narración apócri$f a$. En este texto no se alude para nada ni al futuro de Villasanta ni a su final. Señal oblicua de su recuperada soberanía, el autor manipula y modifica el apócrifo, atribuyéndole una revelación inexistente e incluyéndola en su propia "Narración IV». Cuando el encuadernador cuenta a sus amigos anarquistas la visión del bonzo Ferreiro y Ramiro pregunta si había relatado algo sobre el futuro de Villasanta, el primero responde:

«Sí, dijo que era como una colina de polvo y barro; pero, esto, después de algunos siglos» ${ }^{26}$.

$24 \quad$ Ibid., p. 310

25 De hecho, en la entrada del «Diario» del 10 de junio donde se transcribe una conversación entre don Justo y don Procopio, el primero afirma: «Usted puede reírse todo lo que quiera, pero yo le aseguro que de Villasanta no quedará una sola piedra en pie, lo que se dice una sola piedra». Ibid., p. 52.

26 Ibid., p. 264. 

texto:

La misma función aparecerá duplicada en los dos finales ${ }^{27}$ del

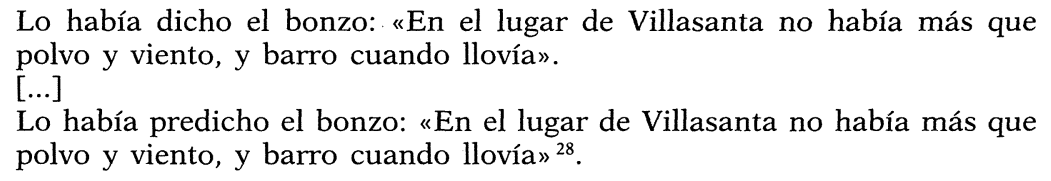

7. La multiplicación de la estrategia del robo de personajes tiene a su último representante en el ya citado autor de las "Secuencias proféticas». En sus narraciones paralelas a las del propio autor-personaje, don Justo Samaniego es propuesto como segundo autor, encargado de elaborar la profecía de la invasión de los vikingos y la consecuente destrucción apocalíptica de Villasanta de la Estrella. El paralelismo inicial que Torrente construye entre los dos narradores sufrirá un significativo desplazamiento. Al elaborar la tipología de Samaniego, éste nos viene presentado, a través de su propia voz, como experto en manuscritos escandinavos (de ahí su credibilidad para la elaboración de la profecía). La gran seguridad en sus capacidades se transparenta en la frase clave que el autor le atribuye:

Yo soy el que soy ${ }^{29}$.

Clara anticipación de su calidad demiúrgica, emblemáticamente anuncia su idoneidad respecto al proceso de transformación del que será objeto. El personaje se impondrá a su autor, iniciando con la apropiación y malogro de varios de sus personajes (el padre Almanzora, los anarquistas, el arzobispo y Lenutchka), continuando con su ciudad (su Villasanta será la que reemplazará la del autor) para finalizar, rizando el rizo metaficcional, con el abandono de autoría por parte del primer narrador.

Torrente estructura este bipolarismo creativo de fuerzas contrarias en una ficción que se resolverá, por su parte, en pérdida. En la voluntaria confusión de los supuestos espacios del discurso y de

27 A partir de la $2 .^{\text {a }}$ edición, incluye, a modo de epílogo, un segundo final que en relidad había sido escrito para la $1 .^{a}$ edición pero que, como revela al final del prólogo, no se había atrevido a publicar.

28 Ibid., pp. 435, 441.

29 Fragmentos, p. 56. Clara referencia bíblica: Dios ( "Éxodo», III). Una frase similar será atribuida al narrador apócrifo, al Supremo: "Soy quien soy", ibid., p. 214. Sobre este argumento en el Quijote, cfr. L. SPITZER, "Soy quien Soy», en Nueva Revista de Filología Hispánica, año 1, n. 2, pp. 113-127. 
la historia, don Justo roba y asaña ${ }^{30}$ a los personajes de las «Narraciones» y del mismo «Diario», debilitando al autor-personaje. El artificio funciona hasta el punto de que éste abandona su partida en manos del personaje al que ha dado más potencia, coherencia, capacidad creativa ${ }^{31}$. El sistema ideado por Samaniego se superpone al del creador porque, en el balance final, el autor reconoce que las «Secuencias proféticas» constituyen el único hilo narrativo llevado a su conclusión. Éste le entrega su obra, su papel, su voz.

La estrategia del robo de los personajes ha dado la vuelta completa pero en espiral, proponiéndose como uno de los ejes y claves de la obra.

En Cervantes el expediente funciona en la destrucción del apócrifo y en la construcción de la propia obra. En Torrente se presenta articulado en los tres registros señalados, el último de los cuales, meollo de literatura, le sirve para cerrar la obra fijando el juego de la precariedad del autor en el punto tangencial entre cero e infinito.

MARÍA A. Roca Mussons Universidad de Florencia

30 Con esta imagen el autor explica el concepto de "asañar»: "La intervención de Samaniego la comparé a esos nidos que los niños manosean cuando los hallan con crías y a los que los padres no vuelven ya. Les llamábamos asañados, y esa fue la palabra que usé cuando le dije a Lenutchka que Samaniego me había asañado el personaje», Fragmentos, p. 368. Desde este punto de vista, la correlación sería: DoN JUSTO=AVELLANEDA; TORRENTE=CERVANTES.

31 La única excepción la constituye la decisión y puesta en acto de la disolución de Lenutchka a quien Samaniego quiere presentar como lesbiana. Las modalidades, a través de las cuales el autor hace desvanecer a Lenutchka, recuerdan la estrategia que utiliza LEWIS CARROL respecto a las desapariciones del gato de Cheshire, sólo que de este lo último que se disuelve es la sonrisa, en cambio de la protagonista queda su bufanda para consuelo o desesperación del amante. 